\title{
Metformin therapy and risk of colorectal adenomas and colorectal cancer in type 2 diabetes mellitus patients: A systematic review and meta-analysis
}

\author{
Feifei Liu ${ }^{1,2}$, Lijing Yan ${ }^{3}$, Zhan Wang ${ }^{3}$, Yuanan Lu ${ }^{4}$, Yuanyuan Chu ${ }^{1,2}$, Xiangyu $\mathbf{L i}^{1,2}$, \\ Yisi Liu ${ }^{1,2}$, Dongsheng Rui ${ }^{5}$, Shaofa $\mathrm{Nie}^{6}$, Hao Xiang ${ }^{1,2}$ \\ ${ }^{1}$ Department of Epidemiology and Biostatistics, School of Public Health, Wuhan University, Wuhan, 430071, China \\ ${ }^{2}$ Global Health Institute, Wuhan University, Wuhan, 430071, China \\ ${ }^{3}$ Global Health Research Center, Duke Kunshan university, Kunshan, Jiangsu, 215316, China \\ ${ }^{4}$ Environmental Health Laboratory, Department of Public Health Sciences, University Hawaii at Manoa, Honolulu, \\ HI 96822 USA \\ ${ }^{5}$ Department Of Public Health, Medicial College Shihezi University, Shihezi city, 832000, China \\ ${ }^{6}$ Department of Epidemiology and Biostatistics and MOE Key Lab of Environment and Health, School of Public Health, Tongji \\ Medical College, Huazhong University of Science and Technology, Wuhan, 430030, China
}

Correspondence to: Hao Xiang, email: xianghao@whu.edu.cn

Keywords: metformin, colorectal adenomas, colorectal cancer, type 2 diabetes mellitus, meta-analysis

Received: September 07, 2016

Accepted: November 16, 2016

Published: December 01, 2016

\section{ABSTRACT}

Recent evidence indicates that metformin therapy may be associated with a decreased colorectal adenoma / colorectal cancer risk in type 2 diabetes patients. However, results are not consistent. We therefore performed a systematic review and meta-analysis to assess the association between metformin therapy and risk of colorectal adenomas / colorectal cancer in type 2 diabetes mellitus patients. We searched the literature published before Aug 31, 2016 in four databases: PubMed, Embase database, CNKI and VIP Library of Chinese Journal. Summary risk estimates (adjusted OR/ adjusted RR/ adjusted HR) with their $95 \%$ confidence interval ( $95 \% \mathrm{CI}$ ) were obtained using a random effects model. Twenty studies (including 12 cohort studies, 7 casecontrol studies and 1 randomized controlled trial study) were selected in terms of data of colorectal adenomas or colorectal cancer incidence. Metformin therapy was found to be associated with a decreased incidence of colorectal adenomas (unadjusted $O R=0.80$, 95\% CI: 0.71-0.90, $p=0.0002$ ). When the adjusted data were analyzed, the summary estimate decreased to $25 \%$ reduction in colorectal adenomas risk (adjusted OR=0.75, 95\% CI: 0.59-0.97, $p=0.03)$. Besides, a significant reduction of colorectal cancer risk was also observed (unadjusted $O R=0.73,95 \% \mathrm{CI}: 0.62-0.86, p=0.0002$ ). And when the adjusted data were analyzed, colorectal cancer risk for metformin users was decreased with a reduction of $22 \%$, compared with non-metformin users and other treatment users (adjusted OR=0.78, 95\% CI: 0.70-0.87, $p<0.00001$ ). Our meta-analysis suggested that metformin therapy may be associated with a decreased risk of colorectal adenomas and colorectal cancer in type 2 diabetes mellitus patients.

\section{INTRODUCTION}

According to WHO, over 220 million people are suffering from diabetes disease. The International Diabetes Federation estimates that the number of people with impaired glucose tolerance will increase to 472 million ( 9 $\%$ of the adult population) by 2025 , and around $40-50 \%$ of them will develop type 2 diabetes mellitus (T2DM) [1]. Many studies have provided strong evidences that population with diabetes disease is at significantly higher risk of developing many forms of cancer, especially for solid tumors. In addition to pancreatic and breast cancer, high incidence of colorectal cancer was also associated with T2DM [2] for metabolic syndromes, especially 
insulin resistance, hyperinsulinemia and hyperglycemia independently [3]. However, recent studies proposed that the risk of colorectal cancer may be reduced among T2DM patients accepting metformin therapy [4-6].

Metformin is a potent anti-hyperglycemic agent. It can reduce hyperinsulinemia, improve insulin resistance [7], and lower blood glucose concentrations in T2DM patients without causing hyperglycemia [8]. Besides, metformin can also reduce glucose uptake from the intestinal tract, improve insulin sensitivity and utilization by adipose tissue and skeletal muscle. Now metformin has been recommended as the first line oral therapy for newly diagnosed T2DM by many professional diabetes organizations.

Some researchers indicated that metformin may be a potential protective factor of colorectal adenomas and colorectal cancer in T2DM patients. Kim et al [9] and Cho et al [10] found that metformin was independently associated with decreased colorectal adenomas incidence. Besides, Tseng et al [11] found that metformin can reduce colorectal cancer risk (adjusted $\mathrm{RR}=0.73$, 95\% CI: 0.58 $0.92, p=0.0115)$. Similar results were also reported in other studies [5, 12, 13]. However, some other studies found no relation between metformin therapy and colorectal adenomas or colorectal cancer $[5,9,14,15]$, thus the results were still inconsistent. Inconsistencies in these results may cause by differences in study design, populations, or different statistical methods. Some researchers have performed systematic reviews and meta-analysis to assess the relationship between metformin use and cancer risk, however, results refer to colorectal cancer were not consistent $[16,17]$, and the review of association between metformin therapy and colorectal adenomas risk has not been published until now. In summary, it is still inconclusive whether use of metformin could protect T2DM patients from colorectal adenomas and colorectal cancer.

To explore associations between metformin therapy and colorectal cancer and adenomas risk, we identified available studies to make a quantitative meta-analysis for the purpose of more cognition of using metformin in T2DM patients. This investigation is important to identify the existing knowledge on the effects of metformin therapy in T2DM patients.

\section{RESULTS}

\section{Search results}

We identified 759 unique papers after searching PubMed, Embase database, China National Knowledge Infrastructure (CNKI), and VIP Library of Chinese Journal. Based on the inclusion and exclusion criteria defined above, we excluded 739 articles. A total of 20 fulltext articles were included in this meta-analysis (Figure $1)$. Among these articles, twelve were cohort studies [4, 5, 9-13, 18-22], seven were case-control studies [14, 15, 23-27] and one was randomized clinical trial (RCT) study [28]. The main characteristics of the 19 observational studies included in the present analysis are reported in Table 1 and Table 2. All observational studies were

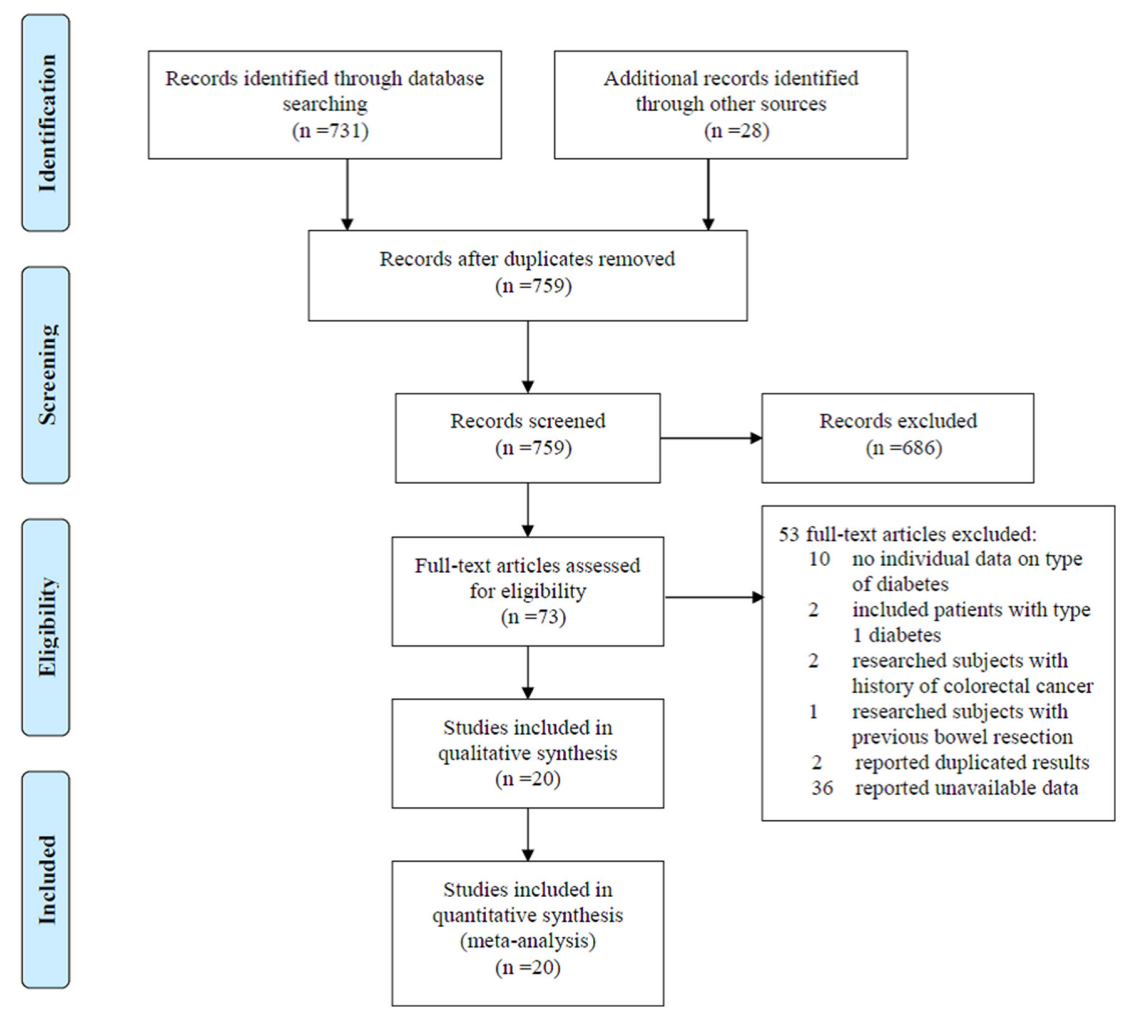

Figure 1: Flow chat of selecting studies for meta-analysis. 
Table 1: Characteristics for publications included in the meta-analysis of metformin and colorectal adenoma

\begin{tabular}{|c|c|c|c|c|c|c|c|c|c|}
\hline \multirow{2}{*}{ First author } & \multirow{2}{*}{ year } & \multirow{2}{*}{ Study type } & \multirow{2}{*}{ Region } & \multirow{2}{*}{ Period } & \multicolumn{2}{|c|}{ Treatment } & \multicolumn{2}{|c|}{ Control } & \multirow{2}{*}{$\begin{array}{c}\text { Adjusted OR/ } \\
\text { RR, 95\%CI }\end{array}$} \\
\hline & & & & & $\mathbf{n}$ & $\mathbf{N}$ & $\mathbf{n}$ & $\mathbf{N}$ & \\
\hline $\begin{array}{l}\text { Yong Woo } \\
\text { Chung [15] }\end{array}$ & 2008 & case-control & Korea & $\begin{array}{l}2003- \\
2006\end{array}$ & 34 & 100 & 45 & 100 & $0.7(0.3-1.4)$ \\
\hline James.D 1[23] & 2008 & case-control & U.S. & $\begin{array}{l}1994- \\
2005\end{array}$ & 414 & 1296 & 1122 & 2952 & - \\
\hline James.D 2[23] & 2008 & case-control & U.S. & $\begin{array}{l}1994- \\
2005\end{array}$ & 351 & 951 & 3367 & 8862 & - \\
\hline James.D 3[23] & 2008 & case-control & U.S. & $\begin{array}{l}1994- \\
2005\end{array}$ & 71 & 159 & 833 & 1666 & - \\
\hline Jain D [27] & 2016 & case-control & Mixed & - & 70 & 211 & 36 & 88 & - \\
\hline $\begin{array}{l}\text { Youn Hee Cho } \\
{[10]}\end{array}$ & 2014 & cohort & Korea & $\begin{array}{l}2001- \\
2013\end{array}$ & 139 & 912 & 450 & 2193 & $\begin{array}{c}0.738(0.554- \\
0.983)\end{array}$ \\
\hline Yo Han Kim [9] & 2015 & cohort & Korea & $\begin{array}{l}2002- \\
2012\end{array}$ & 80 & 151 & 53 & 89 & $\begin{array}{c}0.866(0.453- \\
1.623)\end{array}$ \\
\hline
\end{tabular}

population-based. Quality assessment of The NewcastleOttawa Scale (NOS) showed that publications that met eligibility were of acceptable quality to be included in these meta-analyses (Supplementary Table 1, Table 2).

\section{Metformin therapy and risk of colorectal adenomas}

Five studies, including case-control studies [15, $23,27]$ and cohort studies [9, 10], provided sufficient data to be included in the meta-analysis to evaluate the association between metformin therapy and the risk of colorectal adenomas among T2DM patients. Table 1 shows characteristics of five studies meeting the inclusion criteria and selected for the quantitative analysis. These studies were published after 2007 and mainly conducted in the United States and Korea. While the other study [23] included three different site adenomas and was analyzed separately.

A pooled estimate of $\mathrm{OR}$ and $95 \% \mathrm{CI}$ of association between metformin therapy and colorectal adenomas among the five studies is shown in Figure 2. Metformin therapy was found to be associated with a decreased incidence of colorectal adenomas $(\mathrm{OR}=0.80,95 \% \mathrm{CI}$ : $0.71-0.90, p=0.0002)$. Low between-study heterogeneity was found $\left(\mathrm{I}^{2}=34 \%, p=0.17\right)$ (Figure 2 ).

Subgroup analysis was conducted based on the type of study design. A significant reduction of colorectal adenomas risk was observed in both nested case-control studies (unadjusted $\mathrm{OR}=0.82,95 \%$ CI: 0.72-0.95, $p=0.006$ ) and retrospective cohort studies (unadjusted $\mathrm{OR}=0.71,95 \% \mathrm{CI}: 0.58-0.86, p=0.0004$ ) (Supplementary Figure 1).
When only the adjusted OR estimates from 3 studies $[9,10,15]$ were analyzed, the summary estimate decreased to $25 \%$ reduction in colorectal adenoma risk (adjusted $\mathrm{OR}=0.75,95 \% \mathrm{CI}: 0.59-0.97, p=0.03)$, low between-study heterogeneity was found $\left(\mathrm{I}^{2}=0 \%, p=0.89\right)$ (Supplementary Figure 2).

For we only have five studies refer to metformin therapy and colorectal adenomas risk, the number is too small to conduct the Begg's and Egger's test. However, the funnel plot illustrated a symmetrical distribution of the points, suggesting a lack of publication bias (Supplementary Figure 3).

\section{Metformin therapy and risk of colorectal cancer}

Fifteen studies (Four nested case-control studies [14, 24-26], Ten cohort studies [4, 5, 11-13, 18-22] and one RCT [28]) reported the association between metformin therapy and colorectal cancer risk. Table 2 shows characteristics of all observational studies meeting the inclusion criteria and selected for the quantitative analysis. While two studies $[12,22]$ included two different compare drugs and one studies [21] included different places data of colorectal cancer incidence, data of these three studies were analyzed separately.

Based on data of crude numbers of case and controls, the summary unadjusted odds ratio with the random effects model was 0.73 (95\% CI: 0.62-0.86, $p=0.002$ ) for metformin users (metformin exposure more than 1 year) compared with non-metformin users or other treatment users. High between-study heterogeneity was found $\left(\mathrm{I}^{2}=90 \%, p<0.00001\right)$ (Figure 3 ). 
Table 2: Characteristics for publications included in the meta-analysis of metformin and colorectal cancer

\begin{tabular}{|c|c|c|c|c|c|c|c|c|c|c|c|c|c|c|c|c|c|c|c|c|c|c|}
\hline \multirow[b]{2}{*}{ First author } & \multirow{2}{*}{ year } & \multirow{2}{*}{$\begin{array}{l}\text { Study } \\
\text { type }\end{array}$} & \multirow[b]{2}{*}{ Region } & \multirow{2}{*}{ Period } & \multicolumn{2}{|c|}{ Treatment } & \multicolumn{2}{|c|}{ Control } & \multirow{2}{*}{$\begin{array}{c}\text { Adjusted } \\
\text { OR/ } \\
\text { RR/HR, } \\
95 \% C I\end{array}$} & \multicolumn{13}{|c|}{ Adjust Factors/Covariates } \\
\hline & & & & & $n$ & $\mathbf{N}$ & $\mathbf{n}$ & $\mathbf{N}$ & & Age & Sex & Smoking & Deprivation & $\begin{array}{c}\text { Alcohol } \\
\text { use }\end{array}$ & BMI & HbA1C & $\begin{array}{c}\text { Other } \\
\text { disease }\end{array}$ & $\begin{array}{l}\text { other } \\
\text { drug }\end{array}$ & $\begin{array}{c}\text { CCI } \\
\text { score }\end{array}$ & $\begin{array}{l}\text { diabetes } \\
\text { duration }\end{array}$ & $\begin{array}{l}\text { metformin } \\
\text { duration }\end{array}$ & T-stage \\
\hline $\begin{array}{l}\text { Gillian } \\
\text { Libby [4] }\end{array}$ & 2009 & cohort & UK & $\begin{array}{l}1994- \\
2003\end{array}$ & 40 & 4085 & 76 & 4085 & $\begin{array}{c}0.60(0.38- \\
0.94)\end{array}$ & $\sqrt{ }$ & $\sqrt{ }$ & $\sqrt{ }$ & $\sqrt{ }$ & & $\sqrt{ }$ & $\sqrt{ }$ & & $\sqrt{ }$ & & & & \\
\hline $\begin{array}{l}\text { Meei- } \\
\text { Shyuan Lee } \\
{[18]}\end{array}$ & 2011 & cohort & China & $\begin{array}{l}2000- \\
2007\end{array}$ & 30 & 11221 & 26 & 4213 & $\begin{array}{c}0.36(0.13- \\
0.98)\end{array}$ & $\sqrt{ }$ & $\sqrt{ }$ & & & & & & & $\sqrt{ }$ & $\sqrt{ }$ & & $\sqrt{ }$ & \\
\hline $\begin{array}{l}\text { Michael } \\
\text { Bodmer } \\
{[24]}\end{array}$ & 2011 & $\begin{array}{l}\text { case- } \\
\text { control }\end{array}$ & UK & $\begin{array}{l}1995- \\
2009\end{array}$ & 416 & 920 & 2354 & 5519 & $\begin{array}{c}1.43(1.08- \\
1.90)\end{array}$ & & & $\sqrt{ }$ & & & $\sqrt{ }$ & & & $\sqrt{ }$ & & $\sqrt{ }$ & $\sqrt{ }$ & \\
\hline $\begin{array}{l}\text { Rikje Ruiter } \\
\text { [5] }\end{array}$ & 2012 & cohort & Netherlands & $\begin{array}{l}1998- \\
2008\end{array}$ & 228 & 52698 & 299 & 32591 & $\begin{array}{c}0.91(0.88- \\
0.94)\end{array}$ & $\sqrt{ }$ & $\sqrt{ }$ & & & & & & & $\sqrt{ }$ & & $\sqrt{ }$ & & \\
\hline $\begin{array}{l}\text { Ming-Chia } \\
\text { Hsieh 1[12] }\end{array}$ & 2012 & cohort & China & $\begin{array}{l}2000- \\
2008\end{array}$ & 46 & 3963 & 145 & 6072 & $\begin{array}{c}0.54(0.38- \\
0.75)\end{array}$ & $\sqrt{ }$ & $\sqrt{ }$ & & & & & & & $\sqrt{ }$ & & & & \\
\hline $\begin{array}{l}\text { Ming-Chia } \\
\text { Hsieh 2[12] }\end{array}$ & 2012 & cohort & China & $\begin{array}{l}2000- \\
2008\end{array}$ & 46 & 3963 & 18 & 751 & $\begin{array}{c}0.46(0.27- \\
0.81)\end{array}$ & $\sqrt{ }$ & $\sqrt{ }$ & & & & & & & & & & & \\
\hline $\begin{array}{l}\text { Chin-Hsiao } \\
\text { Tseng [11] }\end{array}$ & 2012 & cohort & China & $\begin{array}{l}2003- \\
2005\end{array}$ & 206 & 26982 & 472 & 61009 & $\begin{array}{c}0.73(0.58- \\
0.92)\end{array}$ & $\sqrt{ }$ & $\sqrt{ }$ & $\sqrt{ }$ & & & & & $\sqrt{ }$ & $\sqrt{ }$ & & $\sqrt{ }$ & $\sqrt{ }$ & \\
\hline $\begin{array}{l}\text { Smiechowski } \\
\text { B [25] }\end{array}$ & $\mathrm{i}_{2013}$ & $\begin{array}{l}\text { case- } \\
\text { control }\end{array}$ & UK & $\begin{array}{l}1998- \\
2009\end{array}$ & 444 & 607 & 4406 & 5837 & $\begin{array}{c}0.94(0.74- \\
1.19)\end{array}$ & & & $\sqrt{ }$ & & & $\sqrt{ }$ & $\sqrt{ }$ & $\sqrt{ }$ & $\sqrt{ }$ & & $\sqrt{ }$ & & \\
\hline $\begin{array}{l}\text { Majken } \\
\text { Cardel [14] }\end{array}$ & 2014 & $\begin{array}{l}\text { case- } \\
\text { control }\end{array}$ & Danish & $\begin{array}{l}2000- \\
2009\end{array}$ & 164 & 1255 & 842 & 5454 & $\begin{array}{c}0.83(0.68- \\
1.00)\end{array}$ & $\sqrt{ }$ & $\sqrt{ }$ & $\sqrt{ }$ & & $\sqrt{ }$ & $\sqrt{ }$ & & & $\sqrt{ }$ & & & $\sqrt{ }$ & \\
\hline $\begin{array}{l}\text { Amikar } \\
\text { Sehdev [26] }\end{array}$ & 2014 & $\begin{array}{l}\text { case- } \\
\text { control }\end{array}$ & U.S. & $\begin{array}{l}2005- \\
2010\end{array}$ & 983 & 2682 & 2059 & 5364 & $\begin{array}{c}0.85(0.76- \\
0.95)\end{array}$ & & & & & & $\sqrt{ }$ & & $\sqrt{ }$ & $\sqrt{ }$ & $\sqrt{ }$ & & $\sqrt{ }$ & \\
\hline $\begin{array}{l}\text { Konstantinos } \\
\text { K [19] }\end{array}$ & 2014 & cohort & UK & $\begin{array}{l}1987- \\
2010\end{array}$ & 353 & 51484 & 246 & 18264 & $\begin{array}{c}0.92(0.76- \\
1.13)\end{array}$ & & & $\sqrt{ }$ & & $\sqrt{ }$ & $\sqrt{ }$ & & & $\sqrt{ }$ & & $\sqrt{ }$ & & \\
\hline $\begin{array}{l}\text { Susan } \\
\text { Spillane } \\
{[20]}\end{array}$ & 2014 & cohort & UK & $\begin{array}{l}2001- \\
2006\end{array}$ & 135 & 241 & 78 & 129 & $\begin{array}{c}0.66(0.39- \\
1.12)\end{array}$ & & & & & & & & & & & & & $\sqrt{ }$ \\
\hline $\begin{array}{l}\text { Hua Xu } \\
1[21]\end{array}$ & 2015 & cohort & U.S. & $\begin{array}{l}1995- \\
2010\end{array}$ & 177 & 2218 & 63 & 903 & $\begin{array}{c}0.50(0.31- \\
0.81)\end{array}$ & $\sqrt{ }$ & $\sqrt{ }$ & $\sqrt{ }$ & & & $\sqrt{ }$ & & $\sqrt{ }$ & $\sqrt{ }$ & & & & \\
\hline $\begin{array}{l}\text { Hua Xu } \\
2[21]\end{array}$ & 2015 & cohort & U.S. & $\begin{array}{l}1995- \\
2010\end{array}$ & 212 & 3029 & 114 & 1629 & $\begin{array}{c}0.60(0.44- \\
0.83)\end{array}$ & $\sqrt{ }$ & $\sqrt{ }$ & $\sqrt{ }$ & & & $\sqrt{ }$ & & $\sqrt{ }$ & $\sqrt{ }$ & & & & \\
\hline $\begin{array}{l}\text { Yu-Ching } \\
\text { Chen [13] }\end{array}$ & 2015 & cohort & China & $\begin{array}{l}1998- \\
2007\end{array}$ & 18 & 2223 & 69 & 3965 & $\begin{array}{c}0.50(0.30- \\
0.81)\end{array}$ & $\sqrt{ }$ & $\sqrt{ }$ & $\sqrt{ }$ & $\sqrt{ }$ & $\sqrt{ }$ & $\sqrt{ }$ & & $\sqrt{ }$ & & & & & \\
\hline $\begin{array}{l}\text { Bernd } \\
\text { Kowall } \\
1[22]\end{array}$ & 2015 & cohort & $\begin{array}{l}\text { Germany } \\
\text { and UK }\end{array}$ & $\begin{array}{l}1995- \\
2013\end{array}$ & 281 & 55988 & 150 & 17704 & $\begin{array}{c}1.05(0.85- \\
1.30)\end{array}$ & $\sqrt{ }$ & $\sqrt{ }$ & & & & $\sqrt{ }$ & & $\sqrt{ }$ & $\sqrt{ }$ & & $\sqrt{ }$ & & \\
\hline $\begin{array}{l}\text { Bernd } \\
\text { Kowall } \\
2[22]\end{array}$ & 2015 & cohort & $\begin{array}{l}\text { Germany } \\
\text { and UK }\end{array}$ & $\begin{array}{l}1995- \\
2013\end{array}$ & 281 & 55988 & 26 & 6571 & $\begin{array}{c}0.97(0.64- \\
1.46)\end{array}$ & $\sqrt{ }$ & $\sqrt{ }$ & & & & $\sqrt{ }$ & & $\sqrt{ }$ & $\sqrt{ }$ & & $\sqrt{ }$ & & \\
\hline
\end{tabular}

\begin{tabular}{|c|c|c|c|c|c|c|c|c|c|}
\hline Study or Subqroup & \multicolumn{2}{|c|}{ Case } & \multicolumn{2}{|c|}{ Control } & Weight & $\begin{array}{c}\text { Odds Ratio } \\
\text { M-H, Random, } 95 \% \mathrm{Cl}\end{array}$ & \multicolumn{3}{|c|}{$\begin{array}{c}\text { Odds Ratio } \\
\text { M-H, Random, } 95 \% \mathrm{Cl}\end{array}$} \\
\hline YongWoo Chung 2008 & 34 & 100 & 45 & 100 & $3.9 \%$ & $0.63[0.36,1.11]$ & & & \\
\hline James.D1 2008 & 414 & 1296 & 1122 & 2952 & $28.8 \%$ & $0.77[0.67,0.88]$ & & & \\
\hline James.D2 2008 & 351 & 951 & 3367 & 8862 & $28.8 \%$ & $0.95[0.83,1.10]$ & & & \\
\hline James.D3 2008 & 71 & 159 & 833 & 1666 & $10.2 \%$ & $0.81[0.58,1.12]$ & & & \\
\hline Youn Hee Cho 2014 & 139 & 912 & 450 & 2193 & $19.2 \%$ & $0.70[0.57,0.86]$ & & & \\
\hline Yo Ham kim 2015 & 80 & 151 & 53 & 89 & $4.5 \%$ & $0.77[0.45,1.30]$ & & & \\
\hline Jain D 2016 & 70 & 211 & 36 & 88 & $4.8 \%$ & $0.72[0.43,1.20]$ & & & \\
\hline Total $(95 \% \mathrm{Cl})$ & & 3780 & & 15950 & $100.0 \%$ & $0.80[0.71,0.90]$ & & & \\
\hline Total events & 1159 & & 5906 & & & & & & \\
\hline $\begin{array}{l}\text { Heterogeneity: } \operatorname{Tau}^{2}=0 \\
\text { Test for overall effect: } Z\end{array}$ & $\begin{array}{l}1 ; \mathrm{Chi}^{2}= \\
3.78(\mathrm{P}=\end{array}$ & $\begin{array}{r}9.07, d \\
0.000\end{array}$ & $=6(\mathrm{P}=$ & $0.17) ;\left.\right|^{2}$ & $=34 \%$ & & $\begin{array}{ll}0.10 .2 & 0.5 \\
\text { Favours [case] }\end{array}$ & $1 \frac{2}{1}$ Favours [c & $\begin{array}{rr}5 & 10 \\
\text { control] }\end{array}$ \\
\hline
\end{tabular}

Figure 2: Forest plot of the association between metformin therapy and colorectal adenomas. 
When the adjusted data estimates from all observational studies were analyzed, the colorectal cancer risk for metformin users was decreased with a reduction of $22 \%$, compared with non-metformin users or other treatment users (adjusted $\mathrm{OR}=0.78,95 \%$ CI: $0.70-0.87$, $p<0.00001)$, the between-study heterogeneity was decreased $\left(\mathrm{I}^{2}=71 \%, p<0.00001\right)$ (Figure 4).

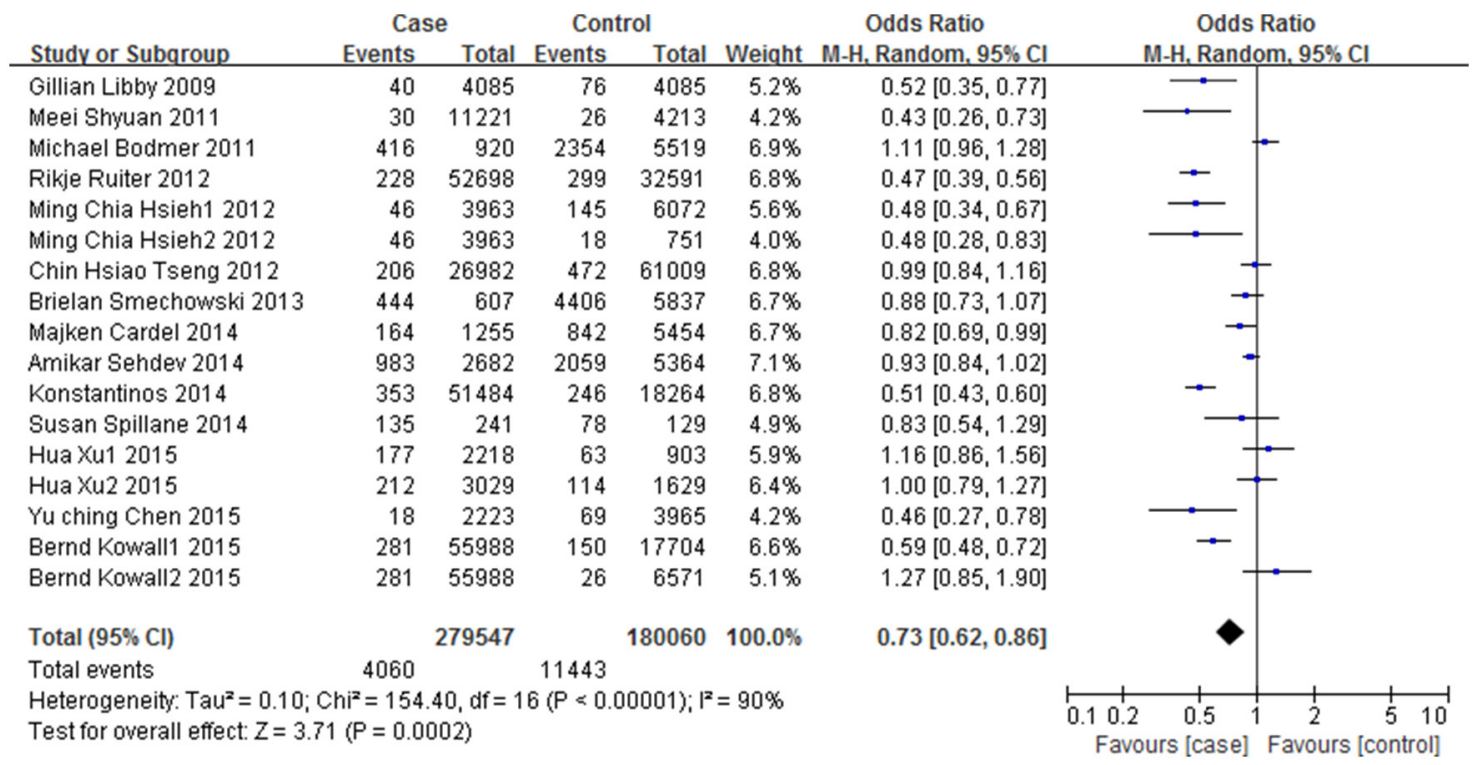

Figure 3: Forest plot of the association between metformin therapy and colorectal cancer - unadjusted odds ratios.

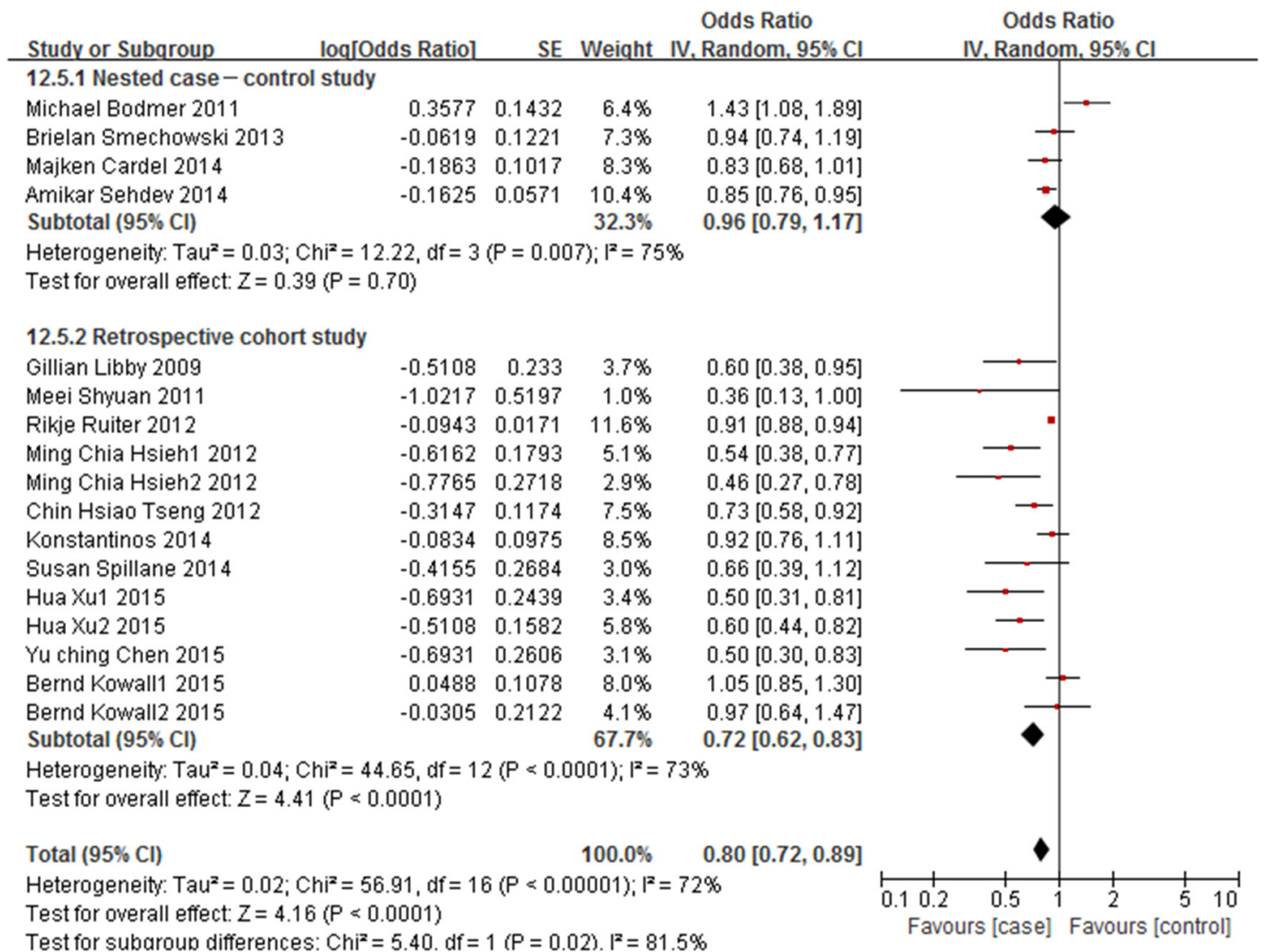

Figure 4: Forest plot of the association between metformin therapy and colorectal cancer - adjusted odds ratios. 
Subgroup analysis was conducted based on the type of study design, no significant relationship was found in nested case-control studies (adjusted $\mathrm{OR}=0.96,95 \% \mathrm{CI}$ : $0.79-1.17, p=0.70)$. However, a significant reduction of colorectal cancer risk was observed in retrospective cohort studies (adjusted OR=0.72, 95\% CI: 0.62-0.83, $p<0.0001$ ) (Figure 4).

As to the meta-analysis on the type of risk estimates (adjusted OR / adjusted RR / adjusted HR), a significant reduction of colorectal cancer risk was observed in adjusted OR data (adjusted OR $=0.85$, 95\% CI: 0.780.92, $p=0.0001)$. High between-study heterogeneity was found $\left(\mathrm{I}^{2}=80 \%, p=0.001\right)$ (Supplementary Figure 4). After omission one of the study [24], the betweenstudy heterogeneity was decreased to $0 \%$. However, no relationship was found with the adjusted RR data (adjusted $\mathrm{RR}=0.83,95 \% \mathrm{CI}$ : 0.65-1.06, $p=0.13$ ). Moderate between-study heterogeneity was found $\left(\mathrm{I}^{2}=55 \%, p=0.14\right)$ (Supplementary Figure 5). And a significant reduction of colorectal cancer risk was observed in adjusted HR data (adjusted HR=0.77, 95\% CI: 0.65-0.91, $p=0.002$ ). Moderate between-study heterogeneity was found $\left(\mathrm{I}^{2}=69 \%, p=0.001\right)($ Supplementary Figure 6$)$

We evaluated the possibility of publication bias in the articles. No obvious publication bias was found by Begg's test $(\mathrm{Z}=1.52, p=0.127)$ (Supplementary Figure 7) and Egger's test ( $\mathrm{t}=-1.40, p=0.182)$ (Supplementary Figure 8). The funnel plot also illustrated a symmetrical distribution of the points, suggesting a lack of publication bias (Figure 5).

\section{DISCUSSION}

This meta-analysis suggests that metformin therapy may be associated with a decreased risk of colorectal adenomas (unadjusted $\mathrm{OR}=0.80,95 \% \mathrm{CI}$ : 0.71-0.90, $p=0.0002$ ) and colorectal cancer (adjusted $\mathrm{OR}=0.70$, 95\% CI: $0.72-0.89, p<0.0001)$ among T2DM patients, compared with non-metformin users and other diabetic drug users. The degree of heterogeneity among studies may cause by the difference in study design, populations or comparators. However, almost all of the results showed a protective effect of metformin.

Our results are consistent with previous observations suggesting a protective role of metformin for colorectal cancer [16, 17, 29]. In 2011, Zhang et al [17] found the metformin therapy was associated with a significantly lower risk of colorectal cancer $(\mathrm{OR}=0.63,95 \% \mathrm{CI}$ : 0.47 0.84, $p=0.002$ ). Similarly, Monica Franciosi et al [29] reported that the risk of colorectal cancer was decreased by $17 \%(\mathrm{OR}=0.83,95 \% \mathrm{CI}: 0.74-0.92, p=0.0009)$. However, Andrea DeCensi et al [16] found an inverse association between metformin use and colon cancer incidence, although not significant ( $\mathrm{SRR}=0.64,95 \% \mathrm{CI}$ : 0.38-1.08). Similarly the RCT study of P.D. Home [28], which was included in our search results, also showed no association between metformin treatment and colorectal cancer risk.

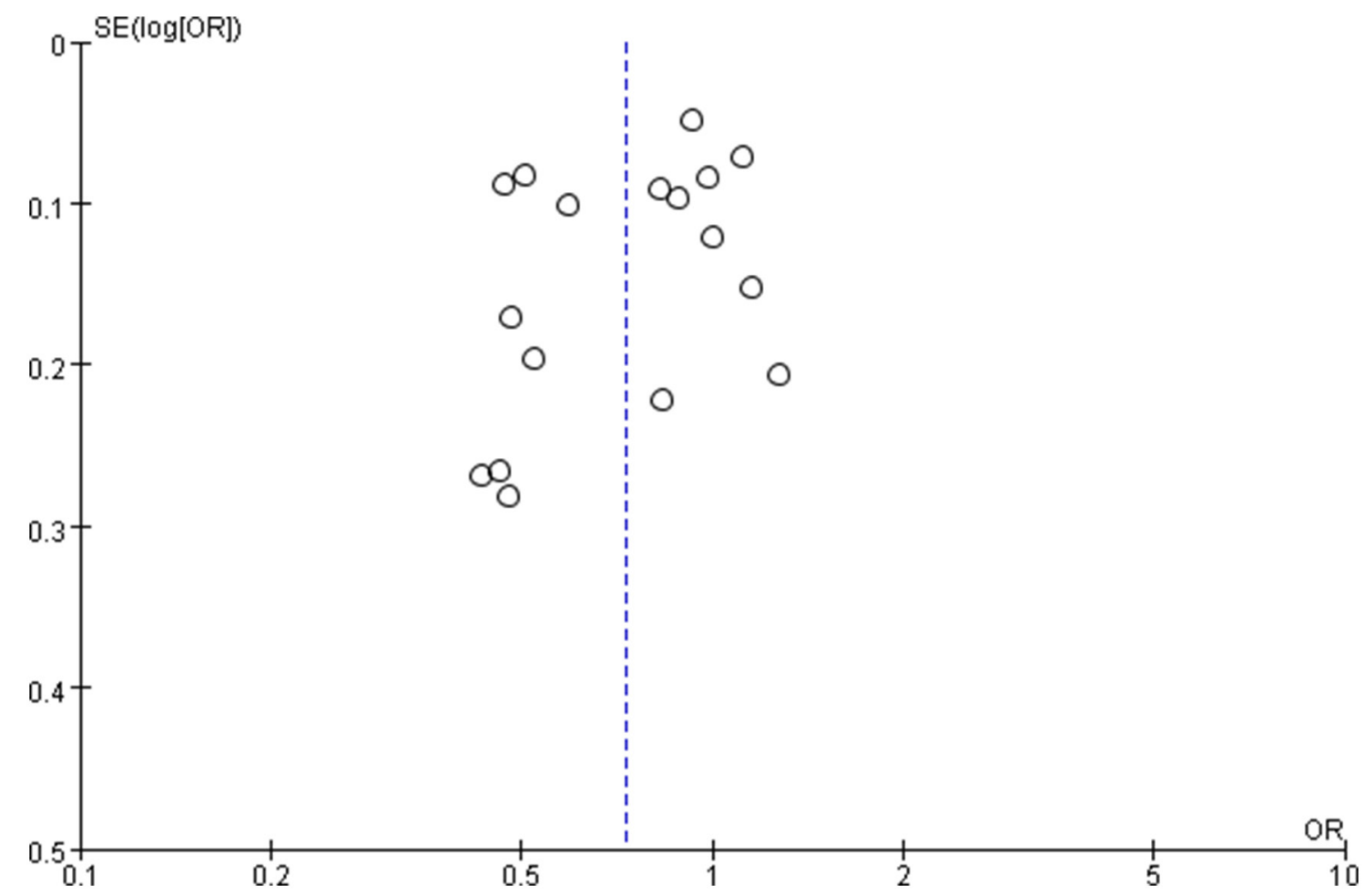

Figure 5: Funnel plot of metformin therapy and colorectal cancer included in meta-analysis. 
These conflicting results may cause by methodological problems within studies: the small number of participants in studies may limit the statistical power to obtain significant results. For example, only 50 participants in the metformin group and 55 participants in the comparison group were included in the RCT study [28].

Metformin also showed a protective effect in many other cancers. A meta-analysis conducted by Wu et al [30] showed that metformin therapy was associated with a significant reduced risk of prostate cancer among cohort studies $(\mathrm{RR}=0.92$, 95\% CI: 0.87-0.96, $p<0.001)$. Zhu et al [32] confirmed that compared with other antidiabetic drugs, metformin was significantly associated with a $16 \%$ reduction of lung cancer risk in T2DM patients $(\mathrm{RR}=0.84$, 95\% CI: $0.73-0.97, p=0.019)$. And a study by Tseng et al [33] proved metformin use is associated with a decreased risk of kidney cancer in patients with T2DM patients $(\mathrm{HR}=0.279$, 95\% CI: 0.254-0.307, $p<0.0001)$. These studies confirmed that metformin therapy may serve as a protective factor in decreasing cancer risk.

Evidences from previous studies indicate that metformin may interfere with carcinogenesis through direct (insulin-independent) and indirect (insulindependent) mechanisms. Metabolic syndromes in T2DM patients such as insulin resistance, hyperinsulinemia and hyperglycemia are risk factors of several cancers $[2,35$, 36]. Metformin can reduce blood glucose directly and can lower insulin resistance and hyperinsulinemia, then may reduce cancer risk among T2DM patients. Meanwhile, cell experiments show that metformin can reduce cell survival by increasing reactive oxygen species, which induce DNA damage and apoptosis [37]. Studies also found metformin can active the intracellular adenosine monophosphateactivated protein kinase (AMPK), which leads to down regulation its downstream target p70S6K (pS6K), resulting in suppression of cellular proliferation, migration and invasion $[6,38]$. However, these investigations are still limited by small sample size, and need to be verified repeatedly by experiment.

Compared with other existing studies, our metaanalysis has several advantages. Firstly, our analysis included a much larger number of studies, and provides more precise results. Sensitivity analysis also indicated that our pooled risk estimates were considerably credible. Secondly, we adopted more rigorous criteria for study selection to ensure the reliability of the meta-analysis, taking into account factors which may affect the results. In addition, we analyzed the results separately by type of diseases (colorectal adenoma and colorectal cancer), which provided a stronger evidence of protective effect of metformin among T2DM patients.

However, our study also has several limitations. Firstly, the selection of populations is inconsistent in different studies, which may be an important source of heterogeneity. Secondly, the description of drug dose and length is unclear among studies. Most studies usually classify metformin as two groups: metformin users vs. non-users or other treatment user. And few studies collected metformin dose data. There might have a dose-response relationship between metformin use and cancer incidence for T2DM patients, and we can't calculate it, which may be another large source of high heterogeneity in our studies. Thirdly, different adjustments may influence the summary estimation of the association between metformin treatment and colorectal adenomas / colorectal cancer risk. Furthermore, the protective effect of metformin may be overestimated due to the association between insulin using and higher risk of colorectal cancer [39]. Future studies need to take all these factors into account and provide more precise results estimate for metformin therapy on colorectal cancer incidence.

In conclusion, our meta-analysis indicates that metformin is associated with a reduction in risk of colorectal adenoma and colorectal cancer incidence in individuals with T2DM, compared with other diabetic treatments. Our results also support the hypothesis that in T2DM patients with high risk for colorectal adenomas / colorectal cancer (due to their metabolic condition), the candidates for drug therapy may better be treated with metformin. And further prospective studies, especially large-scale clinical studies and cell experiments are needed to confirm the relationship between colorectal cancers and metformin treatment.

\section{MATERIALS AND METHODS}

Our meta-analysis was in accordance with the Systematic Reviews and Meta-Analysis guidelines: PRISMA Checklist.

\section{Search strategies}

A comprehensive literature search was performed in the PubMed, Embase database, China National Knowledge Infrastructure (CNKI) and VIP Library of Chinese Journal from their earliest available data to Aug 31, 2016. The following search terms and combinations were used in keyword and subject heading search: ("diabetes" or "diabetes mellitus" or "DM" or "insulin resistance") and ("therapy" or "treatment" or "therapeutics" or "therapeutics" or "metformin" or "biguanides") and (("colorectal" or "colon" or "rectal" or "rectum") or ("neoplasm" or "neoplasia" or "cancer" or "tumor" or "carcinoma" or "adenoma")). Only human studies were included. The languages of included articles were limited to English and Chinese. A manual search was also conducted for references cited in the selected articles. (refer supplementary for detailed search strategy).

\section{Inclusion and exclusion criteria}

We applied five inclusion criteria on retrieved articles. The eligible paper should: (1) be an original article; (2) report randomized or observational studies; (3) 
study patients with T2DM ; (4) have metformin therapy as the first treatment (metformin exposure more than 1 year) compared with non-metformin user (never use metformin) and other treatments (insulin, sulfonylurea, thiazolidinedione etc.); (5) provide relative risk (RR), odds ratio (OR) or hazard ratio (HR) with their 95\% confidence interval $(95 \% \mathrm{CI})$, or provide sufficient data to allow adequate estimation of the RR / OR and 95\% CI. We dropped the paper if it: (1) cases report, summary, review or meta-analysis; (2) had no individual data on type of diabetes; (3) included patients with type 1 diabetes; (4) researched subjects with complication (diabetic retinopathy etc.), hereditary colorectal syndromes, history of colorectal cancer, chronic inflammatory bowel disease, or previous bowel resection; (5) reported duplicated results or unavailable data.

\section{Data extraction}

Two authors (FFL and HX) selected studies independently according to the inclusion and exclusion criteria listed above. The characteristics extracted were the name of first author, publication year, study design, race, study period, adjust factor or covariance, crude numbers of exposed and unexposed subjects, crude numbers of colorectal adenomas / colorectal cancer in exposed group and unexposed group (for cohort studies), or crude numbers of cases and controls, crude numbers of colorectal adenomas / colorectal cancer in case and control group (for case-control studies), RR, OR or HR with their $95 \%$ CI. When there were multiple publications from the same population, only the study with largest sample size were included. Conflicts of data extraction between the two reviewers were resolved by discussion and consensus with an arbitrator (SFN).

\section{Quality assessment}

Two authors (DSR and YSL) conducted quality assessment of included observational studies (cohort study and case-control study) independently according to The Newcastle-Ottawa Scale (NOS)[41]. This scale includes eight items, which are divided into three parts: Selection, Comparability and Outcome. After evaluating these three domains of each individual study, it could be scored a maximum of nine stars. A study earning seven or more stars was seen to be of high quality. Conflicts of the results of quality assessment were resolved by discussion and consensus with an arbitrator (SFN).

\section{Statistical analysis}

In this meta-analysis, we used a random-effects model to estimate the pooled effect across studies for the association between metformin therapy and the risk of colorectal adenomas / colorectal cancer. For the randomeffects model accounts for variations between studies in addition to sampling error within studies [42]. We calculated the summary OR, RR and HR with $95 \%$ CI with specific adjusted data taken directly from the study or estimated by crude numbers for the association between metformin therapy and colorectal adenomas / colorectal cancer. Heterogeneity among studies was evaluated using $\mathrm{I}^{2}$ statistics [43]. $\mathrm{I}^{2}>75.0 \%, 50.0-75.0 \%$ and $\mathrm{I}^{2}$ $<50 \%$ indicate low, moderate, and high heterogeneity respectively. Sensitivity analysis was conducted to identify studies contributing disproportionately to the observed heterogeneity, by omitting a study at a time to analyze the influence of individual studies on the summary estimate [42]. The significance of the pooled OR, RR or HR was determined by the Z-test, and $p$ value less than 0.05 was considered statistically significant. RevMan (Version 5.2) was used for these calculations.

The possibility of publication bias, which may be caused by the non-publication of small number of studies with negative findings, was assessed with a funnel plot for asymmetry. Besides, the Begg's test and Egger's test were also conducted to assess the publication bias [44]. The meta-analysis was considered to have significant publication bias if the $p$ value was less than 0.05 . These analyses were carried out with Stata (Version 12.0).

\section{CONFLICTS OF INTEREST}

The authors have no conflicts of interest to disclose.

\section{GRANT SUPPORT}

This study was supported by National Natural Science Foundation of China (Grant No. 81402743 and Grant No. 81172752); Hubei Province Health and Family Planning Scientific Research Project (Grant No. WJ2015Q023); The Fundamental Research Funds for the Central Universities (Grant No. 2042016kf0165).

\section{REFERENCES}

1. Pawałowska M, Markowska A. The influence of metformin in the etiology of selected cancers. Współczesna Onkologia. 2012; 3:223-229.

2. Anwar MA, Kheir WA, Eid S, Fares J, Liu X, Eid AH, Eid AA. Colorectal and Prostate Cancer Risk in Diabetes: Metformin, an Actor behind the Scene. Journal of Cancer. 2014; 5:736-744.

3. Hang J, Cai B, Xue P, Wang L, Hu H, Zhou Y, Ren S, Wu J, Zhu M, Chen D, Yang H. The Joint Effects of Lifestyle Factors and Comorbidities on the Risk of Colorectal Cancer: A Large Chinese Retrospective Case-Control Study. PLoS One. 2015; 10:e0143696.

4. Libby G, Donnelly LA, Donnan PT, Alessi DR, Morris AD, Evans JMM. New Users of Metformin Are at Low Risk of 
Incident Cancer: A cohort study among people with type 2 diabetes. Diabetes Care. 2009; 32:1620-1625.

5. Ruiter R, Visser LE, van Herk-Sukel MP, Coebergh JWW, Haak HR, Geelhoed-Duijvestijn PH, Straus SM, Herings RM, Stricker BH. Lower Risk of Cancer in Patients on Metformin in Comparison With Those on Sulfonylurea Derivatives: Results from a large population-based follow-up study. Diabetes Care. 2012; 35:119-124.

6. Tan BK, Adya R, Chen J, Lehnert H, Sant Cassia LJ, Randeva HS. Metformin treatment exerts antiinvasive and antimetastatic effects in human endometrial carcinoma cells. J Clin Endocrinol Metab. 2011; 96:808-816.

7. Ashokkumar N, Pari L, Rao Ch A. Effect of N-benzoylD-phenylalanine and metformin on insulin receptors in neonatal streptozotocin-induced diabetic rats: studies on insulin binding to erythrocytes. Arch Physiol Biochem. 2006; 112:174-181.

8. Viollet B, Guigas B, Sanz Garcia N, Leclerc J, Foretz M, Andreelli F. Cellular and molecular mechanisms of metformin: an overview. Clin Sci (Lond). 2012; 122:253-270.

9. Kim YH, Noh R, Cho SY, Park SJ, Jeon SM, Shin HD, Kim SB, Shin JE. Inhibitory Effect of Metformin Therapy on the Incidence of Colorectal Advanced Adenomas in Patients With Diabetes. Intestinal Research. 2015; 13:145.

10. Cho YH, Ko BM, Kim SH, Myung YS, Choi JH, Han JP, Hong SJ, Jeon SR, Kim HG, Kim JO, Lee MS. Does Metformin Affect The Incidence of Colonic Polyps and Adenomas in Patients with Type 2 Diabetes Mellitus? Intestinal Research. 2014; 12:139.

11. Tseng CH. Diabetes, metformin use, and colon cancer: a population-based cohort study in Taiwan. European Journal of Endocrinology. 2012; 167:409-416.

12. Hsieh M-C, Lee T-C, Cheng S-M, Tu S-T, Yen M-H, Tseng $\mathrm{C}-\mathrm{H}$. The Influence of Type 2 Diabetes and GlucoseLowering Therapies on Cancer Risk in the Taiwanese. Experimental Diabetes Research. 2012; 2012:1-6.

13. Kok V, Chen Y-C, Chien C-H, Horng J-T, Tsai J. Cancer risk in patients aged 30 years and above with type 2 diabetes receiving antidiabetic monotherapy: a cohort study using metformin as\&nbsp;the comparator. Therapeutics and Clinical Risk Management. 2015:1315.

14. Cardel M, Jensen SM, Pottegård A, Jørgensen TL, Hallas J. Long-term use of metformin and colorectal cancer risk in type II diabetics: a population-based case-control study. Cancer Medicine. 2014; 3:1458-1466.

15. Chung YW, Han DS, Park KH, Eun CS, Yoo KS, Park $\mathrm{CK}$. Insulin therapy and colorectal adenoma risk among patients with Type 2 diabetes mellitus: a case-control study in Korea. Dis Colon Rectum. 2008; 51:593-597.

16. DeCensi A, Puntoni M, Goodwin P, Cazzaniga M, Gennari A, Bonanni B, Gandini S. Metformin and Cancer Risk in Diabetic Patients: A Systematic Review and Meta-analysis. Cancer Prevention Research. 2010; 3:1451-1461.
17. Zhang ZJ, Zheng ZJ, Kan H, Song Y, Cui W, Zhao G, Kip KE. Reduced Risk of Colorectal Cancer With Metformin Therapy in Patients With Type 2 Diabetes: A meta-analysis. Diabetes Care. 2011; 34:2323-2328.

18. Lee M-S, Hsu C-C, Wahlqvist ML, Tsai H-N, Chang Y-H, Huang Y-C. Type 2 diabetes increases and metformin reduces total, colorectal, liver and pancreatic cancer incidences in Taiwanese: a representative population prospective cohort study of 800,000 individuals. BMC Cancer. 2011; 11:20.

19. Tsilidis KK, Capothanassi D, Allen NE, Rizos EC, Lopez DS, van Veldhoven K, Sacerdote C, Ashby D, Vineis P, Tzoulaki I, Ioannidis JP. Metformin does not affect cancer risk: a cohort study in the U.K. Clinical Practice Research Datalink analyzed like an intention-to-treat trial. Diabetes Care. 2014; 37:2522-2532.

20. Spillane S, Bennett K, Sharp L, Barron TI. Metformin exposure and disseminated disease in patients with colorectal cancer. Cancer Epidemiology. 2014; 38:79-84.

21. Xu H, Aldrich MC, Chen Q, Liu H, Peterson NB, Dai Q, Levy M, Shah A, Han X, Ruan X, Jiang M, Li Y, Julien JS, Warner J, Friedman C, Roden DM, et al. Validating drug repurposing signals using electronic health records: a case study of metformin associated with reduced cancer mortality. Journal of the American Medical Informatics Association. 2014.

22. Kowall B, Stang A, Rathmann W, Kostev K. No reduced risk of overall, colorectal, lung, breast, and prostate cancer with metformin therapy in diabetic patients: database analyses from Germany and the UK. Pharmacoepidemiology and Drug Safety. 2015; 24:865-874.

23. Lewis JD, Capra AM, Achacoso NS, Ferrara A, Levin TR, Quesenberry CP, Habel LA. Thiazolidinedione Therapy Is Not Associated With Increased Colonic Neoplasia Risk in Patients With Diabetes Mellitus. Gastroenterology. 2008; 135:1914-1923.e1911.

24. Bodmer M, Becker C, Meier C, Jick SS, Meier CR. Use of Metformin Is Not Associated with a Decreased Risk of Colorectal Cancer: A Case-Control Analysis. Cancer Epidemiology Biomarkers \& Prevention. 2011; 21:280-286.

25. Smiechowski B, Azoulay L, Yin H, Pollak MN, Suissa $\mathrm{S}$. The Use of Metformin and Colorectal Cancer Incidence in Patients with Type II Diabetes Mellitus. Cancer Epidemiology Biomarkers \& Prevention. 2013; 22:1877-1883.

26. Sehdev A, Shih Y-CT, Vekhter B, Bissonnette MB, Olopade OI, Polite BN. Metformin for primary colorectal cancer prevention in patients with diabetes: A case-control study in a US population. Cancer. 2015; 121:1071-1078.

27. Jain D, Chhoda A, Uribe J. Effect of Insulin and Metformin Combination Treatment on Colon Adenoma and Advanced Adenoma Among DM II. Journal of Gastrointestinal Cancer. 2016. 
28. Home PD, Kahn SE, Jones NP, Noronha D, Beck-Nielsen $\mathrm{H}$, Viberti G. Experience of malignancies with oral glucoselowering drugs in the randomised controlled ADOPT (A Diabetes Outcome Progression Trial) and RECORD (Rosiglitazone Evaluated for Cardiovascular Outcomes and Regulation of Glycaemia in Diabetes) clinical trials. Diabetologia. 2010; 53:1838-1845.

29. Federici M, Franciosi M, Lucisano G, Lapice E, Strippoli GFM, Pellegrini F, Nicolucci A. Metformin Therapy and Risk of Cancer in Patients with Type 2 Diabetes: Systematic Review. PLoS One. 2013; 8:e71583.

30. Wu GF, Zhang XL, Luo ZG, Yan JJ, Pan SH, Ying XR, Pan JG, Zhang GF. Metformin therapy and prostate cancer risk: a meta-analysis of observational studies. Int J Clin Exp Med. 2015; 8:13089-13098.

31. Wang CP, Lehman DM, Lam YW, Kuhn JG, Mahalingam D, Weitman S, Carlos L, Downs JR, Stuart E, Hernandez J, Thompson IM, Ramirez A. Metformin for Reducing Racial/ Ethnic Difference in Prostate Cancer Incidence for Men with Type 2 Diabetes. Cancer Prev Res (Phila). 2016.

32. Zhu N, Zhang Y, Gong YI, He J, Chen X. Metformin and lung cancer risk of patients with type 2 diabetes mellitus: A meta-analysis. Biomed Rep. 2015; 3:235-241.

33. Tseng $\mathrm{CH}$. Use of metformin and risk of kidney cancer in patients with type 2 diabetes. Eur J Cancer. 2016; 52:19-25.

34. Chen YC, Kok VC, Chien CH, Horng JT, Tsai JJ. Cancer risk in patients aged 30 years and above with type 2 diabetes receiving antidiabetic monotherapy: a cohort study using metformin as the comparator. Ther Clin Risk Manag. 2015; 11:1315-1323.

35. Yang YX, Hennessy S, Lewis JD. Insulin therapy and colorectal cancer risk among type 2 diabetes mellitus patients. Gastroenterology. 2004; 127:1044-1050.
36. Esposito K, Chiodini P, Colao A, Lenzi A, Giugliano D. Metabolic syndrome and risk of cancer: a systematic review and meta-analysis. Diabetes Care. 2012; 35:2402-2411.

37. Nair V, Sreevalsan S, Basha R, Abdelrahim M, Abudayyeh A, Rodrigues Hoffman A, Safe S. Mechanism of Metformin-dependent Inhibition of Mammalian Target of Rapamycin (mTOR) and Ras Activity in Pancreatic Cancer. Journal of Biological Chemistry. 2014; 289:27692-27701.

38. Kwan HT, Chan DW, Cai PC, Mak CS, Yung MM, Leung TH, Wong OG, Cheung AN, Ngan HY. AMPK activators suppress cervical cancer cell growth through inhibition of DVL3 mediated Wnt/beta-catenin signaling activity. PLoS One. 2013; 8:e53597.

39. Sun A, Liu R, Sun G. Insulin therapy and risk of colorectal cancer: an updated meta-analysis of epidemiological studies. Current Medical Research and Opinion. 2013; 30:423-430.

40. Moher D, Liberati A, Tetzlaff J, Altman DG. Preferred reporting items for systematic reviews and meta-analyses: the PRISMA statement. PLoS Med. 2009; 6:e1000097.

41. Stang A. Critical evaluation of the Newcastle-Ottawa scale for the assessment of the quality of nonrandomized studies in meta-analyses. Eur J Epidemiol. 2010; 25:603-605.

42. Borenstein M, Hedges LV, Higgins JP, Rothstein HR. A basic introduction to fixed-effect and random-effects models for meta-analysis. Res Synth Methods. 2010; 1:97-111.

43. Higgins JP, Thompson SG, Deeks JJ, Altman DG. Measuring inconsistency in meta-analyses. BMJ. 2003; 327:557-560.

44. Egger M, Davey Smith G, Schneider M, Minder C. Bias in meta-analysis detected by a simple, graphical test. BMJ. 1997; 315:629-634. 